\title{
ethanol $+\mathrm{H}_{2} \mathrm{O} \rightarrow \mathrm{H}_{2}+\mathrm{CO}_{2}$
}

\section{$\mathrm{H}_{2}$ yield $(700 \mathrm{~K})$}

$\{100\}$

$\{110\}$

$\{111\}$

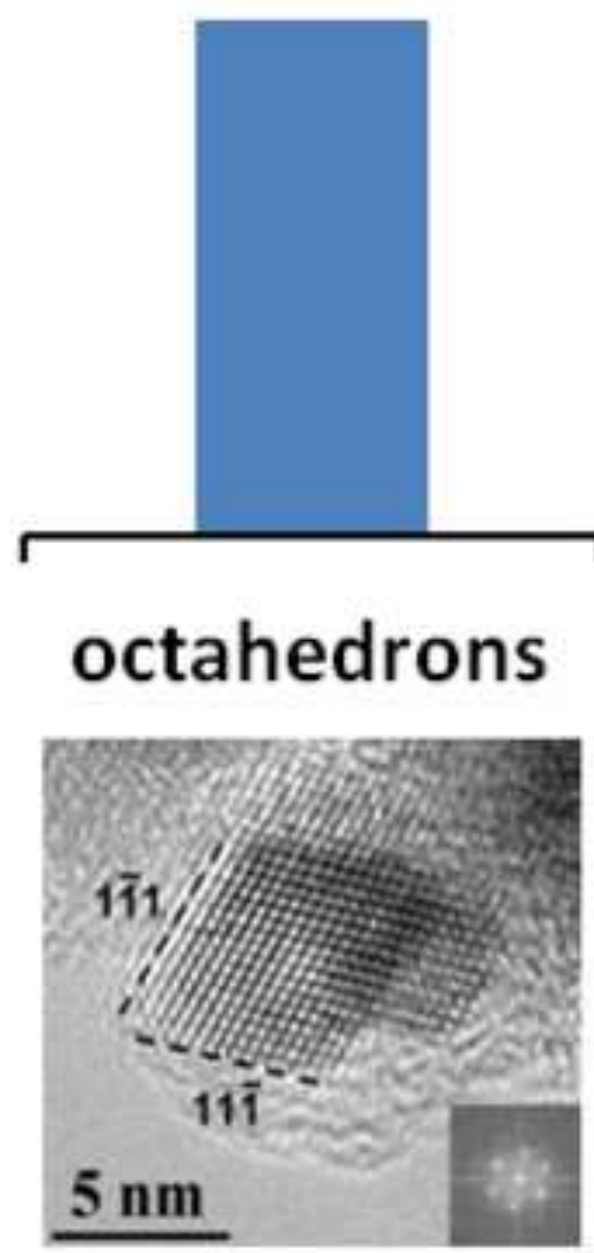

rods

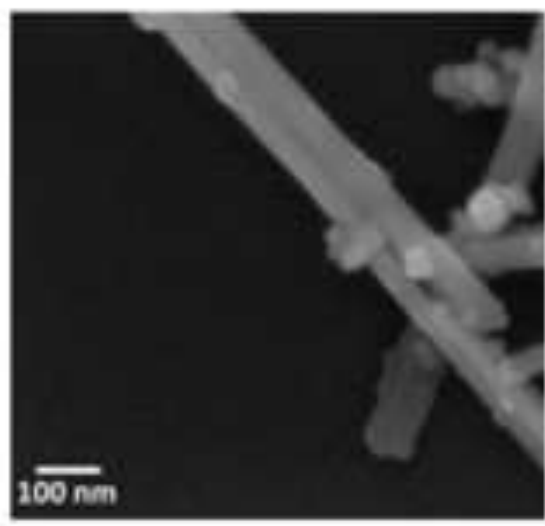

cubes

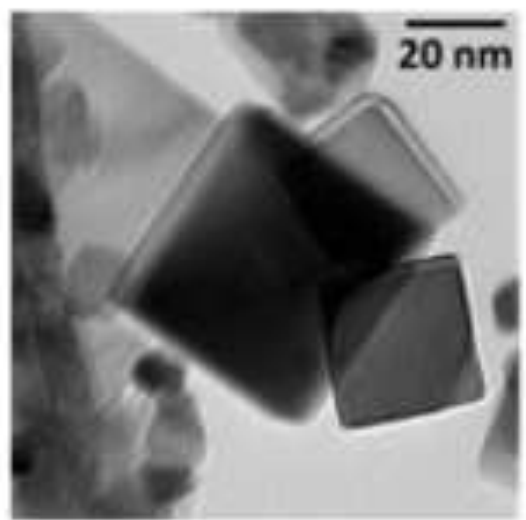




\title{
The influence of nano-architectured $\mathrm{CeO}_{\mathrm{x}}$ supports in $\mathrm{RhPd} / \mathrm{CeO}_{2}$ for the catalytic ethanol steam reforming reaction
}

\author{
N.J. Divins ${ }^{1}$, A. Casanovas ${ }^{1}$, W. $\mathrm{Xu}^{2}$, S.D. Senanayake ${ }^{2}$, D. Wiater ${ }^{3}$, A. Trovarelli ${ }^{3}$, J. \\ Llorca $^{1, *}$
}

${ }^{1}$ Institute of Energy Technologies and Centre for Research in NanoEngineering, Universitat Politècnica de Catalunya. Diagonal 647, 08028 Barcelona, Spain

${ }^{2}$ Chemistry Department, Brookhaven National Laboratory, Upton, NY 11973, USA

${ }^{3}$ Dipartimento di Chimica, Fisica e Ambiente, Università di Udine, 33100 Udine, Italy

${ }^{*}$ Corresponding author:

Prof. Jordi Llorca

Institut de Tècniques Energètiques

Universitat Politècnica de Catalunya

Av. Diagonal 647, Ed. ETSEIB, 08028 Barcelona, Spain

Tel.: (+34) 934011708

Fax.: (+34) 934017149

e-mail: jordi.llorca@upc.edu 


\section{Abstract}

The ethanol steam reforming (ESR) reaction has been tested over RhPd supported on polycrystalline ceria in comparison to structured supports composed of nanoshaped $\mathrm{CeO}_{2}$ cubes and $\mathrm{CeO}_{2}$ rods tailored towards the production of hydrogen. At $650-700 \mathrm{~K}$ the hydrogen yield follows the trend $\mathrm{RhPd} / \mathrm{CeO}_{2}$-cubes $>\mathrm{RhPd} / \mathrm{CeO}_{2}$-rods $>\mathrm{RhPd} / \mathrm{CeO}_{2^{-}}$ polycrystalline, whereas at temperatures higher than $800 \mathrm{~K}$ the catalytic performance of all samples is similar and close to the thermodynamic equilibrium. The improved performance of $\mathrm{RhPd} / \mathrm{CeO}_{2}$-cubes and $\mathrm{RhPd} / \mathrm{CeO}_{2}$-rods for ESR at low temperature is mainly ascribed to higher water-gas shift activity and a strong interaction between the bimetallic - oxide support interaction. STEM analysis shows the existence of $\mathrm{RhPd}$ alloyed nanoparticles in all samples, with no apparent relationship between ESR performance and RhPd particle size. X-ray diffraction under operating conditions shows metal reorganization on $\{100\}$ and $\{110\}$ ceria crystallographic planes during catalyst activation and ESR, but not on $\{111\}$ ceria crystallographic planes. The RhPd reconstructing and tuned activation over ceria nanocubes and nanorods is considered the main reason for better catalytic activity with respect to conventional catalysts based on polycrystalline ceria. 


\section{Introduction}

Alcohols represent an emerging and alternative source of liquid fuels to the most commonly derived fossil fuel feedstocks used nowadays for hydrogen production since they can be produced renewably from biomass. Among them, bio-ethanol constitutes an important source that seems to be particularly suitable due to its easy and broadly implemented production [1]. There are three main catalytic pathways to produce hydrogen directly from ethanol that differ by the co-reactant used, the process chemistry and the maximum hydrogen yield achievable. These include steam reforming, partial oxidation, and its combination, autothermal reforming [2]. The optimum hydrogen production can be achieved by steam refoming (ESR), where ethanol reacts with steam to give carbon dioxide and hydrogen: $\mathrm{C}_{2} \mathrm{H}_{6} \mathrm{O}+3 \mathrm{H}_{2} \mathrm{O} \rightarrow 2 \mathrm{CO}_{2}+6 \mathrm{H}_{2}$. The key challenge remains the ability to scale down the ESR to smaller devices and employ lower temperatures by minizing cost and improving efficency.

In the last two decades many studies have been devoted to ESR using supported copper, nickel, cobalt and noble metal catalysts [3]. An efficient catalyst for hydrogen production from ethanol has to dissociate the $\mathrm{C}-\mathrm{C}$ bond, maintain low $\mathrm{CO}$ concentration and also be stable under catalytic operation conditions (avoid coke accumulation). Catalysts based on nickel and cobalt tend to sinter under reaction conditions and have a strong propensity for the methanation process [4,5]. In contrast, noble metals, and in particular $\mathrm{Rh}$ and $\mathrm{Ru}$, are known to successfully break the C-C bond leading to less coke deposition and thus results in more stable catalysts. As first reported by the Idriss' group, the bimetallic Rh-Pd system supported over $\mathrm{CeO}_{2}$ has shown excellent catalytic performance for ESR, with a delicate interaction between the bimetallic nanoparticles and the oxide support [6]. The cooperative 
effect of C-C bond cleavage provided by Rh together with hydrogen recombination favored by $\mathrm{Pd}$ and the simultaneous dissociation of $\mathrm{H}_{2} \mathrm{O}$ and oxygen mobility provided by $\mathrm{CeO}_{2}$ results in a highly active, selective and stable multifunctional catalyst for ESR [7]. Thus, $\mathrm{RhPd} / \mathrm{CeO}_{2}$ catalysts have been successfully employed in a catalytic membrane reactor to yield pure hydrogen from ethanol [8] and used in a fuel reformer for direct PEM fuel cell feeding [9] as well as in microdevices using raw bio-ethanol [10]. The fundamental source of this catalytic performance remains poorly understood and is the key to further improving applicability.

Ceria is a key component for many reforming catalysts and often shows a strong dependence on morphology. In fact, shape-dependent activity of ceria has already been recognized in catalytic CO oxidation [11-14], NO reduction [15], water-gas shift reaction $[16,17]$ and soot combustion [18]. The energy required to form oxygen vacancies on the \{111\} surface of $\mathrm{CeO}_{2}$ is higher than those on $\{110\}$ and $\{100\}$ surfaces, so the concentration of oxygen vacancies on differents planes of ceria is different [19]. There are more oxygen vacancies on $\{110\}$ and $\{100\}$ planes, which are favorable for the catalytic reactions outlined above. Notably, when oxygen vacancies are not required for reaction to occour, an opposite effect can be observed with $\{111\}$ faces showing a higher reactivity [20]. Polycrystalline ceria nanoparticles usually consist of octahedra or truncated octahedra shapes, which mainly expose the most stable $\{111\}$ facets in order to minimize surface energy, whereas nanorods are terminated by $\{110\}$ and $\{100\}$ planes and nanocubes expose $\{100\}$ planes. The $\{110\}$ and $\{100\}$ planes often expose a higher density of unsaturated cationic sites than $\{111\}$ planes, which is a richer source of active sites. In addition, more oxygen vacancies can be accommodated on the surface of ceria nanorods and nanocubes with respect to conventional, polycrystalline ceria. As the 
number of vacancies increases, the movement of oxygen atoms in the lattice becomes easier, the abilitiy to dissociate reactants (i.e. $\mathrm{H}_{2} \mathrm{O}$ ) improves and the increased diffusion rate of oxygen in the lattice results in increased catalytic activity [21].

With respect to reforming reactions, the morphology dependence of ceria-based catalysts has been studied in methane dry reforming over $\mathrm{Ni} / \mathrm{CeO}_{2}$ [22], methanol steam reforming over $\mathrm{Au} / \mathrm{CeO}_{2}$ [23], ethanol oxidative steam reforming over $\mathrm{Rh} / \mathrm{CeO}_{2} / \mathrm{Al}_{2} \mathrm{O}_{3}$ [24], and ethanol steam reforming over $\mathrm{Co} / \mathrm{CeO}_{2}[25,26]$. Although there is as yet no consensus on the effect of the ceria nanoshape on the catalyst selectivity, the catalysts containing nanorods and nanocubes exhibited higher coke resistance compared with polyhedral ceria catalysts. It has been claimed that oxygen storage and release can occur both at the surface and in the bulk of ceria nanorods and nanocubes but it is restricted only to the surface of nanopolyhedra [27]. This would benefit the gasification of coke deposits [28]. In this work we test the ethanol steam reforming reaction over RhPd supported on ceria nanocubes, nanorods and nanopolyhedra and use synchrotron radiation to perform operando X-ray diffraction studies and scanning transmission electron microscopy for structural characterization, in an effort to elucidate the role of oxide structure on the ESR reaction.

\section{Experimental}

\subsection{Catalyst preparation}

Two types of shape-controlled nanoceria supports (nanocubes and nanorods) were prepared according to previously reported methodologies [18, 29-31]. For ceria nanocubes 
$\left(\mathrm{CeO}_{2}-\mathrm{C}\right)$ a $\mathrm{NaOH}$ solution $(57.60 \mathrm{~g} \mathrm{NaOH}$ dissolved in $210 \mathrm{~mL}$ of distilled water) was added dropwise into a $\mathrm{Ce}\left(\mathrm{NO}_{3}\right)_{3} \cdot 6 \mathrm{H}_{2} \mathrm{O}$ solution $\left(5.21 \mathrm{~g}\right.$ of $\mathrm{Ce}\left(\mathrm{NO}_{3}\right)_{3} \cdot 6 \mathrm{H} 2 \mathrm{O}$ in $30 \mathrm{~mL}$ of distilled water) under vigorous stirring. After precipitation, the suspension was transferred into a Teflon-lined cylinder and sealed in a stainless steel autoclave. The suspension was heated for $24 \mathrm{~h}$ at $453 \mathrm{~K}$ and, after cooling, the mixture was centrifuged and washed three times with water and then with ethanol for separation and purification of the powder, which was dried at $333 \mathrm{~K}$ overnight and calcined under air atmosphere at $723 \mathrm{~K}$ for $4 \mathrm{~h}$. Ceria nanorods $\left(\mathrm{CeO}_{2}-\mathrm{R}\right)$ were prepared by adding dropwise a $\mathrm{NaOH}$ solution $(75.59 \mathrm{~g} \mathrm{NaOH}$ dissolved in $200 \mathrm{~mL}$ of distilled water) into a solution of $\mathrm{CeCl}_{3} \cdot 7 \mathrm{H}_{2} \mathrm{O}(5.36 \mathrm{~g}$ in $40 \mathrm{~mL}$ of distilled water). After precipitation and transfer to autoclave, the mixture was heated at $410 \mathrm{~K}$ for $48 \mathrm{~h}$, followed by cooling, separation, washing, drying and calcination at $723 \mathrm{~K}$ as explained above for the $\mathrm{CeO}_{2}-\mathrm{C}$ support. Conventional polycrystalline ceria $\left(\mathrm{CeO}_{2}-\mathrm{P}\right)$ was prepared by precipitation of a homogeneous acidic solution of cerium chloride with a base. The filter cake was washed with distilled water, followed by drying and calcination at $873 \mathrm{~K}$ for 6 hours to obtain a powder having surface area comparable to that of the nanoshaped $\mathrm{CeO}_{2}-\mathrm{C}$ and $\mathrm{CeO}_{2}-\mathrm{R}$ supports $\left(30-40 \mathrm{~m}^{2} \cdot \mathrm{g}^{-1}\right)$. Noble metals $(3 \% \mathrm{w} / \mathrm{w}$ total with respect to the ceria support, $\mathrm{Rh}: \mathrm{Pd}=1: 1$ molar) were added in a single step by incipient wetness impregnation, using a water/acetone $\mathrm{PdCl}_{2}$ and $\mathrm{RhCl}_{3}$ solution. Samples were dried at $373 \mathrm{~K}$ and calcined in air at $573 \mathrm{~K}$. The resulting catalyst samples are referred to as $\mathrm{RhPd} / \mathrm{CeO}_{2}-\mathrm{P}, \mathrm{RhPd} / \mathrm{CeO}_{2}-$ $\mathrm{C}$ and $\mathrm{RhPd} / \mathrm{CeO}_{2}-\mathrm{R}$.

\subsection{Catalyst characterization}

Temperature-programmed reaction experiments in conjunction with XRD were performed at beamline X7B $(\lambda=0.3196 \AA)$ of the National Synchrotron Light Source (NSLS) at Brookhaven National Laboratory (BNL). Powder samples of 2-3 mg were loaded in a quartz capillary $(0.7$ 
mm ID) mounted in a flow cell system [32,33]. Quartz wool was added to both ends of the sample powder to keep its position under gas flow and heating. A resistance heating coil enclosed the sample capillary, and a K-type thermocouple was placed inside the capillary in the quartz wool next to the sample. A temperature controller read the temperature of the thermocouple and adjusted the output voltage applied to the heating coil. Two-dimensional transmission diffraction data was collected on a Perkin Elmer amorphous silicon detector. The catalyst samples were consecutively exposed to: (i) $\mathrm{O}_{2}$ from room temperature up to $573 \mathrm{~K}$ at $5 \mathrm{~K} \cdot \mathrm{min}^{-1}$; (ii) $\mathrm{H}_{2}$ at $573 \mathrm{~K}$ for 30 minutes; (iii) $\mathrm{He}$ from 573 to $773 \mathrm{~K}\left(5 \mathrm{~K} \cdot \mathrm{min}^{-1}\right)$; (iv) a mixture of water-ethanol (steam-to-carbon $(\mathrm{S} / \mathrm{C})$ ratio $\mathrm{S} / \mathrm{C}=3, \mathrm{ESR}$ ) at $773 \mathrm{~K} ;(\mathrm{v}) \mathrm{ESR}$ at $873 \mathrm{~K}$; and (vi) ESR at $973 \mathrm{~K}$. The outlet of the capillary reactor was monitored on-line with a Cirrus MKS mass spectrometer. Scanning transmission electron microscopy (STEM) images and energy electron loss spectra (EELS) were collected with a Cs-corrected Hitachi HD$2700 \mathrm{C}$ operated at $200 \mathrm{kV}$.

\subsection{Catalytic tests}

The ESR reaction evaluation was accomplished at $600-1050 \mathrm{~K}$ and atmospheric pressure in a lab-scale set up. Before reaction, samples were reduced at $573 \mathrm{~K}$ for $1 \mathrm{~h}$ in $10 \% \mathrm{H}_{2} / \mathrm{N}_{2}$. A liquid feed mixture of ethanol and water with steam to carbon ratio $(S / C)$ of 3 was provided directly from a storage tank by an HPLC pump (Knauer Smartline). Heating tapes were used for feed evaporation and overheating sections before the furnace. After collecting the condensable components from the reactor, the gaseous effluent stream was quantitatively evaluated in terms of volumetric total flowrate (bubble soap meter) and composition. A micro GC (Agilent 3000A) equipped with MS 5A, Plot U and Stabilwax capillary columns and TCD detectors were used to measure on-line gas concentrations every $5 \mathrm{~min}$. An undiluted reactant mixture (ethanol and water, no inert gas) was used, with a feed load of 
WHSV $=9 \cdot 10^{-3} \mathrm{NL}_{\text {gas }} \cdot g_{\text {catalyst }}{ }^{-1} \cdot \mathrm{s}^{-1}$, which accounted for a GHSV value of $10^{4} \mathrm{~h}^{-1}$. The main products of the reaction were $\mathrm{H}_{2}, \mathrm{CO}_{2}, \mathrm{CO}$ and $\mathrm{CH}_{4}$. Only trace amounts of acetaldehyde was detected for operation at low temperatures, whereas negligible amounts of other products such as ethane, ethylene and acetone were measured. Outlet molar flowrates of the non-condensable components $\left(\mathrm{H}_{2}, \mathrm{CO}_{2}, \mathrm{CO}\right.$ and $\left.\mathrm{CH}_{4}\right)$ were calculated from the measured composition by GC and the total volumetric flowrate of the gaseous outlet stream, whereas outlet flowrates of ethanol and water were evaluated by closing element balances. The hydrogen yield was calculated after normalization to the maximum theoretical moles of $\mathrm{H}_{2}$ per mole of ethanol fed that can be produced through the ESR reaction (which is 6): $Y_{\mathrm{H} 2}=n_{H 2} / 6 n_{E t O H, i n}$. Product selectivity was calculated on a dry basis as: $S_{i}=100\left(n_{i} / \Sigma_{i} n_{i}\right)$.

\section{Results and discussion}

\subsection{Catalytic performance}

The hydrogen yield obtained over the $\mathrm{RhPd} / \mathrm{CeO}_{2}-\mathrm{P}, \mathrm{RhPd} / \mathrm{CeO}_{2}-\mathrm{C}$ and $\mathrm{RhPd} / \mathrm{CeO}_{2}-\mathrm{R}$ catalysts as well as over the bare $\mathrm{CeO}_{2}-\mathrm{P}, \mathrm{CeO}_{2}-\mathrm{C}$ and $\mathrm{CeO}_{2}-\mathrm{R}$ supports during the ESR reaction at various temperatures is presented in Figure 1. It is clear that in all cases the ESR process takes place to a larger extent when the noble metals are supported on ceria as compared to the bare supports, as reported elsewhere $[7,8,10]$. It is also evident that higher temperatures favor the reforming process, in accordance with the endothermic character of the reaction. It is important to note that bare ceria supports show similar catalytic performance at each reaction condition tested, without dependence on the shape of the support. In contrast, this is not the case for the samples loaded with RhPd. Clearly, at low reaction temperatures $(650-700 \mathrm{~K})$ the hydrogen yield attained is remarkably higher for the 
$\mathrm{RhPd} / \mathrm{CeO}_{2}-\mathrm{C}$ catalyst, followed by $\mathrm{RhPd} / \mathrm{CeO}_{2}-\mathrm{R}$ and, finally, $\mathrm{RhPd} / \mathrm{CeO}_{2}-\mathrm{P}$. This implies that structure sensitivity is important when the bimetallic interacts with the oxide support structure. In this temperature range, the hydrogen yield obtained over the catalyst containing ceria nanocubes is about $60 \%$ higher than that of the conventional catalyst prepared with polycrystalline ceria. When the reaction temperature is increased up to $800 \mathrm{~K}$, the hydrogen yield for all three catalysts is comparable. The higher hydrogen yield attained with $\mathrm{RhPd} / \mathrm{CeO}_{2}-\mathrm{C}$ and $\mathrm{RhPd} / \mathrm{CeO}_{2}-\mathrm{R}$ catalysts with respect to that obtained for $\mathrm{RhPd} / \mathrm{CeO}_{2}-\mathrm{P}$ cannot be ascribed to differences in ethanol conversion values, since at low temperatures $(<700 \mathrm{~K})$ ethanol conversion differs less than $14 \%$ among the different catalysts and is similar at higher temperatures $(>800 \mathrm{~K})$.

Figure 2 shows the selectivity for $\mathrm{H}_{2}, \mathrm{CO}_{2}, \mathrm{CO}$ and $\mathrm{CH}_{4}$ corresponding to the ESR tests performed over the $\mathrm{RhPd} / \mathrm{CeO}_{2}$ catalysts. The product distribution obtained at different temperatures is in accordance with the main reaction scheme already reported for this type of catalysts [7]. First, ethanol undergoes decomposition at low temperature: $\mathrm{C}_{2} \mathrm{H}_{6} \mathrm{O} \rightarrow \mathrm{H}_{2}+$ $\mathrm{CO}+\mathrm{CH}_{4}$, which can be seen in Figure 2 as $\left[\mathrm{H}_{2}\right] \sim[\mathrm{CO}] \sim\left[\mathrm{CH}_{4}\right]$ at $600 \mathrm{~K}$. At this temperature, however, the amount of hydrogen produced is slightly larger than that of carbon monoxide and methane, especially for the $\mathrm{RhPd} / \mathrm{CeO}_{2}-\mathrm{C}$ catalyst, suggesting that dehydrogenation of ethanol also operates at low temperature. Then, at intermediate temperatures the water gas shift (WGS) reaction takes place: $\mathrm{CO}+\mathrm{H}_{2} \mathrm{O} \rightarrow \mathrm{H}_{2}+\mathrm{CO}_{2}$, with the concomitant increase in the hydrogen yield attained. Simultaneously, the reforming of methane with steam (MSR) also occurs: $\mathrm{CH}_{4}+\mathrm{H}_{2} \mathrm{O} \rightarrow 3 \mathrm{H}_{2}+\mathrm{CO}$, which is favored at high temperatures. The optimum ESR operating temperature should be carefully chosen to maximize the hydrogen yield since higher temperatures are preferred for MSR but this may result in the reverse WGS 
reaction, which is detrimental for production of hydrogen. From the data presented in Figure 2, it is interesting to note that the WGS activity is much higher for the $\mathrm{RhPd} / \mathrm{CeO}_{2}-\mathrm{C}$ and $\mathrm{RhPd} / \mathrm{CeO}_{2}-\mathrm{R}$ catalysts when compared to that of $\mathrm{RhPd} / \mathrm{CeO}_{2}-\mathrm{P}$. The $\mathrm{RhPd} / \mathrm{CeO}_{2}-\mathrm{C}$ and $\mathrm{RhPd} / \mathrm{CeO}_{2}-\mathrm{R}$ samples are very active for the WGS at about $700 \mathrm{~K}$ (dashed line), whereas for the $\mathrm{RhPd} / \mathrm{CeO}_{2}-\mathrm{P}$ sample the maximum WGS activity is reached at much higher temperatures, $800-900 \mathrm{~K}$. Concerning methane steam reforming, all three catalysts performed similarly. Therefore, the higher hydrogen yield values reported in Figure 1 for the $\mathrm{RhPd} / \mathrm{CeO}_{2}-\mathrm{C}$ and $\mathrm{RhPd} / \mathrm{CeO}_{2}-\mathrm{R}$ catalysts with respect to the $\mathrm{RhPd} / \mathrm{CeO}_{2}-\mathrm{P}$ sample at low temperature $(650-700 \mathrm{~K})$ are most likely due to a better WGS performance. At high temperature $(>800 \mathrm{~K})$, the hydrogen yield obtained over the three samples becomes similar because the products distribution is the same for all catalysts and equals the thermodynamic equilibrium values. Accordingly, the hydrogen yields obtained over the bare supports are similar in all the temperature range tested because in the absence of RhPd they exhibit similar WGS activity.

We can conclude that ESR performance over nanoshaped ceria doped with RhPd is closely related to its WGS activity, and together with the fact that the $\mathrm{RhPd} / \mathrm{CeO}_{2}$ catalysts tested exhibited different WGS activity whereas it was similar over bare nanoshaped ceria supports, it provides a new opportunity to assess on the shape dependence activity of ceria-based catalysts. It has been claimed that highly dispersed active species on $\mathrm{CeO}_{2}$ nanomaterials are responsible for the catalytic activity in the WGS reaction $[34,35]$. On the other hand, the dispersion of the active species on ceria usually shows a strong structural sensibility. Generally speaking, the oxygen vacancies favor the dispersion of active species. To get insight into the structural characteristics of our $\mathrm{RhPd} / \mathrm{CeO}_{2}$ catalysts we have studied them by STEM and XRD under operando conditions. We have used operando 
XRD because we have recently shown that strong restructuring of the ceria-supported RhPd nanoparticles occurs under ESR conditions, which induces strong changes to the behavior of the catalyst [36].

\subsection{STEM characterization}

Figure 3 shows STEM images corresponding to the as prepared $\mathrm{RhPd} / \mathrm{CeO}_{2}-\mathrm{P}$ catalyst. The sample is composed of metal nanoparticles supported on polycrystalline $\mathrm{CeO}_{2}$ nanocrystals of about $15-25 \mathrm{~nm}$ in size and exhibiting abundant $\{111\}$ crystallographic planes, as expected. The metal nanoparticles range from 1.5 to $3 \mathrm{~nm}$. It should be noted that most of the metal nanoparticles do not show crystallographic ordering, indicating a strong interaction between the metal atoms and the polycrystalline $\mathrm{CeO}_{2}$ support particles. The bimetallic composition of the metal nanoparticles was confirmed by electron energy loss spectroscopy (EELS) carried out on individual nanoparticles. In those metal particles with discernable lattice spacings, the values recorded were 2.21-2.23 and 1.91-1.93 $\AA$ and are consistent with the (111) and (200) crystallographic planes of alloyed RhPd species, respectively [37]. Several STEM images corresponding to the as prepared $\mathrm{RhPd} / \mathrm{CeO}_{2}-\mathrm{C}$ catalyst are shown in Figure 4. The sample is comprised by well-developed $\mathrm{CeO}_{2}$ nanocubes of about 20-35 $\mathrm{nm}$ in size and metal nanoparticles of about 1.5-3 nm. The ceria nanocubes exhibit almost exclusively the $\{100\}$ family planes $((200)$ planes at $2.71 \AA)$. Metal particles with well-defined lattice spacings at 2.21-2.23 $\AA$ are ascribed to (111) crystallographic planes of the RhPd alloy. As reported above, individual metal nanoparticles were analyzed by EELS and in all cases a bimetallic composition was encountered. Figure 5 shows STEM images corresponding to the as prepared $\mathrm{RhPd} / \mathrm{CeO}_{2}-\mathrm{R}$ catalyst as well as representative $\mathrm{EEL}$ spectra. The sample is composed of metal nanoparticles of about 1.2-1.8 nm in size, supported on $\mathrm{CeO}_{2}$ nanorods of about 30-50 nm width and 200-500 nm length, which exhibit 
both $\{110\}$ and $\{100\}$ as well as a minor amount of $\{111\}$ crystallographic planes. Therefore, in the fresh catalysts, $\mathrm{Rh}$ and $\mathrm{Pd}$ are encountered as alloyed nanoparticles over the different ceria nanoshaped supports and their size follows the trend: $\mathrm{RhPd}_{\text {ceria nanocubes }} \sim \mathrm{RhPd}_{\text {ceria }}$

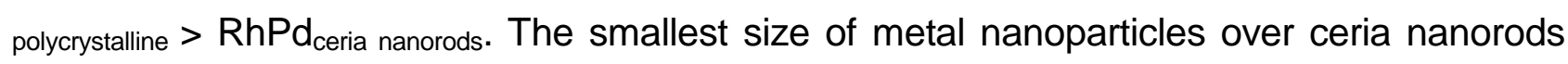
has already been reported for $\mathrm{Au} / \mathrm{CeO}_{2}$ and has been ascribed to the different coordination capacity of the exposed $\{110\}$ planes [16]. However, no apparent relationship exists in our case between the RhPd particle size and the hydrogen yield observed (Figure 1).

\subsection{Operando XRD characterization}

Figure 6 shows the XRD profiles corresponding to $d_{h k l}$ from 1.7 to $2.9 \AA$ recorded over the $\mathrm{RhPd} / \mathrm{CeO}_{2}-\mathrm{P}, \mathrm{RhPd} / \mathrm{CeO}_{2}-\mathrm{C}$ and $\mathrm{RhPd} / \mathrm{CeO}_{2}-\mathrm{R}$ catalysts under operando conditions in: (i) oxygen (the equivalent of the catalysts as prepared), (ii) hydrogen (the activation treatment of the catalysts prior to ESR tests) and (iii) ESR atmospheres ( $\mathrm{S} / \mathrm{C}=3$, similar to the catalyst testing conditions). In this $d_{h k l}$ range the (220) and (200) crystallographic planes of $\mathrm{CeO}_{2}$ at 1.91 and $2.71 \AA$ are visible along with the (111) crystallographic plane of RhPd at 2.20-2.25 $\AA$. In accordance with the STEM results outlined above, the as prepared catalysts (calcined at $573 \mathrm{~K}$ ) contain $\mathrm{RhPd}$ nanoparticles in the range $1.2-3 \mathrm{~nm}$ in size, which escape detection by XRD (in the XRD profile of the $\mathrm{RhPd} / \mathrm{CeO}_{2}-\mathrm{P}$ sample only a weak signal of $\mathrm{RhPd}$ is observed). However, during activation of the samples under hydrogen at $573 \mathrm{~K}$, the XRD patterns of $\mathrm{RhPd} / \mathrm{CeO}_{2}-\mathrm{C}$ and $\mathrm{RhPd} / \mathrm{CeO}_{2}-\mathrm{R}$ catalysts vary significantly, whereas that of $\mathrm{RhPd} / \mathrm{CeO}_{2}-\mathrm{P}$ sample does not. The $\mathrm{XRD}$ profile of the $\mathrm{RhPd} / \mathrm{CeO}_{2}-\mathrm{C}$ catalyst shows an intense asymmetric peak with a shoulder at low $d_{h k l}$ values. The appearance of this peak can be ascribed to a reorganization accompanied by an increase of the crystallinity of the $\mathrm{RhPd}$ nanoparticles, and its asymmetry is indicative of the presence of more than one type 
of $\mathrm{RhPd}$ alloy ( $\mathrm{Rh}$ and $\mathrm{Pd}$ are miscible at this temperature in a wide range, [38]). A similar XRD peak is recorded for $\mathrm{RhPd}$ over the sample $\mathrm{RhPd} / \mathrm{CeO}_{2}-\mathrm{R}$ after the reduction treatment, but with a much lower intensity, which can be explained by a smaller particle size of RhPd nanoparticles on ceria nanorods compared to that of RhPd nanoparticles on ceria nanocubes in accordance with STEM results. In contrast, on polycrystalline ceria, the XRD signal corresponding to $\mathrm{RhPd}$ nanoparticles does not show significant differences with respect to the XRD profile before reduction, which indicates that there is no reorganization of the metals in RhPd nanoparticles. This represents a strong difference between polycrystalline ceria and ceria nanocubes and nanorods as supports for RhPd nanoparticles and also means that $\{111\}$ ceria crystallographic planes limit the metal atomic reorganization on their surface, whereas on $\{100\}$ and $\{110\}$ ceria crystallographic planes the reorganization of RhPd nanoparticles is much easier, which can be related to their higher surface energy. Under ESR at $873 \mathrm{~K}$, the $\mathrm{XRD}$ profiles of the $\mathrm{RhPd} / \mathrm{CeO}_{2}-\mathrm{P}$ catalyst do not show significant variations, again pointing out the quenching character of the low surface energy $\{111\}$ ceria crystallographic planes. In contrast, the XRD patterns of $\mathrm{RhPd} / \mathrm{CeO}_{2}-\mathrm{C}$ and $\mathrm{RhPd} / \mathrm{CeO}_{2}-\mathrm{R}$ catalysts recorded under ESR show differences with respect to the samples before reaction. In both cases, the peak ascribed to RhPd decreases its intensity and, in particular for the $\mathrm{RhPd} / \mathrm{CeO}_{2}-\mathrm{R}$ catalyst, the peak broadens considerably, which can be related to a further metal atomic reorganization during reaction. The XRD patterns recorded under ESR at 773, 873 , and $973 \mathrm{~K}$ for each catalyst are similar. The morphology of the ceria nanoshapes was maintained during the experiments since no significant differences in the relative intensities and $\mathrm{FWHM}$ of the $\mathrm{CeO}_{2}$ peaks were observed.

Therefore, the better catalytic performance in the ESR reaction over $\mathrm{RhPd} / \mathrm{CeO}_{2}$ catalysts containing ceria nanocubes and nanorods with respect to conventional $\mathrm{RhPd} / \mathrm{CeO}_{2}$ catalysts 
containing polycrystalline ceria could be likely related to the capability of metal reorganization on $\{100\}$ and $\{110\}$ ceria crystallographic planes induced by the gaseous surrounding environments. From the catalytic tests, this atomic reorganization has a particular effect on the WGS performance (one of the main reactions participating in the ESR mechanism), which occurs at a lower temperature over the $\mathrm{RhPd} / \mathrm{CeO}_{2}-\mathrm{C}$ and $\mathrm{RhPd} / \mathrm{CeO}_{2}-\mathrm{R}$ catalysts when compared to the $\mathrm{RhPd} / \mathrm{CeO}_{2}-\mathrm{P}$ sample. Our systematic studies show that the $\mathrm{C}-\mathrm{C}$ and $\mathrm{O}-\mathrm{H}$ bond breaking (WGS) is strongly coupled to the structure of the RhPd alloy and its interaction with the cerium oxide support at low temperatures. The propensity of the RhPd to dissociate the C-C bond is clearly influenced by the structure of the support. The relative degree of WGS performance on the other hand is likely a product of the chemical properties of the oxide support including the extent of reducibility, oxygen transport and prevalence of undercoordinated sites. It is also highly probable that the predominant surface architecture of the oxide support and abundance of $\mathrm{Ce}^{3+}$ likely imparts a distinct influence to the strength of the energetics related to the bitemallic nanoparticles, stability of adsorbates (ethanol, $\mathrm{H}_{2} \mathrm{O}$ ), strength of intermediates (ethoxy, $\mathrm{OH}$ ) and ultimately may influence the prevailing reaction mechanism. This aspect of the work is as yet unexplored.

\section{Conclusions}

A RhPd/CeO 2 catalyst containing ceria nanocubes performs better in the ethanol steam reforming (ESR) to produce hydrogen at low temperature $(<700 \mathrm{~K})$ than a $\mathrm{RhPd} / \mathrm{CeO}_{2}$ catalyst containing ceria nanorods and both perform better than a conventional $\mathrm{RhPd} / \mathrm{CeO}_{2}$ catalyst prepared by using polycrystalline ceria. The likely reasons for differences in catalytic 
performance arise mainly from the structural influence of the catalyst on the efficiency in C-C bond breaking and the activity of the catalysts in the water gas shift reaction, which are important steps involved in the mechanism of the ESR over the $\mathrm{RhPd} / \mathrm{CeO}_{2}$ system. A detailed structural characterization by STEM and XRD under operando conditions indicates that the better catalytic activity exhibited by RhPd supported on ceria nanocubes and nanorods is likely related to relative strength of the bimetallic-oxide support interaction and the enhanced capability of metal reorganization over $\{100\}$ and $\{110\}$ crystallographic planes of ceria with respect to that over the low surface energy $\{111\}$ planes of ceria.

\section{Acknowledgments}

This work has been funded through grant MINECO ENE2012-36368. J.L. is Serra Húnter Fellow and is grateful to ICREA Academia program. Work performed at Brookhaven National Laboratory was supported by the U.S. Department of Energy, Office of Science, Office of Basic Energy Sciences, and Catalysis Science Program under contract No. DEAC02-98CH10886. This work used resources of the National Synchrotron Light Source, which is a DOE Office of Science User Facility.

\section{References}

[1] A. Le Valant, A. Garron, N. Bion, D. Duprez, F. Epron, Int. J. Hydrogen Energ. 36 (2011) 311-318.

[2] N. Bion, D. Duprez, F. Epron, ChemSusChem 5 (2012) 76-84. 
[3] J. Llorca, V. Cortés, N.J. Divins, R. Olivera, E. Taboada, Renewable Hydrogen Technologies, Eds. L.M. Gandía, G. Arzamendi, P.M. Diéguez, Elsevier, Amsterdam, 2013; Ch. 7, pp. 135-169.

[4] F. Frusteri, S. Freni, V. Chiodo, S. Donato, G. Bonura, S. Cavallaro, Int. J. Hydrogen Energ. 31 (2006) 2193-2199.

[5] R. Espinal, E. Taboada, E. Molins, R.J. Chimentao, F. Medina, J. Llorca, Appl. Catal. B: Environ. 127 (2012) 59-67.

[6] M. Scott, M. Goeffrey, W. Chiu, M.A. Blackford, H. Idriss, Top. Catal. 51 (2008) 13-21.

[7] H. Idriss, M. Scott, J. Llorca, S. Chan, W. Chiu, P. Sheng, A. Yee, M. Blackford, S.

Pas, A. Hill, F. Alamgir, R. Rettew, C. Petersburg, S. Senanayake, M. Barteau, ChemSusChem 1 (2008) 905-910.

[8] E. López, N. J. Divins, J. Llorca, Catal. Today 193 (2012) 145-150.

[9] R. Koch, E. López, N.J. Divins, M. Allué, A. Jossen, J. Riera, J. Llorca, Int. J. Hydrogen Energ. 38 (2013) 5605-5615.

[10] N. Divins, E. López, A. Rodríguez, D. Vega, J. Llorca, Chem. Eng. Process. 64 (2013) $31-37$.

[11] X-S. Huang, H. Sun, L-C. Wang, Y-M. Liu, K-N. Fan, Y. Cao, Appl. Catal. B: Environ. 90 (2009) 224-232.

[12] J.W. Qin, J.F. Lu, M.H. Cao, C.W. Hu, Nanoscale 2 (2010) 2739-2743.

[13] P.X. Huang, F. Wu, B.L. Zhu, X.P. Gao, H.Y. Zhu, T.Y. Yan, W.P. Huang, S.H. Wu, D.Y. Song, J. Phys. Chem. B 109 (2005) 19169-19174.

[14] E. Aneggi, J. Llorca, M. Boaro, A. Trovarelli, J. Catal. 234 (2005) 88-95.

[15] L. Liu, Z. Yao, Y. Deng, F. Gao, B. Liu, L. Dong, ChemCatChem 3 (2011) 978-989.

[16] N. Yi, R. Si, H. Saltsburg, M. Flytzani-Stephanopoulos, Energy Environ. Sci. 3 (2010) 831-837. 
[17]R. Si, M. Flytzani-Stephanopoulos, Angew. Chem., Int. Ed., 47 (2008) 2884-2887.

[18] E. Aneggi, D. Wiater, C. de Leitenburg, J. Llorca, A. Trovarelli, ACS Catalysis 4 (2014) 172-181.

[19] M. Abid, V. Paul-Boncour, R. Touroude, Appl. Catal. A: Gen. 297 (2006) 48-59.

[20] G. Vilè, S. Colussi, F. Krumeich, A. Trovarelli, J. Perez-Ramirez, Angew. Chem. Int. Ed. 53 (2014) 12069-12072.

[21] X. Weng, J.K. Cockcroft, G. Hyett, M. Vickers, P. Boldrin, C.C. Tang, S.P. Thompson, J.E. Parker, J.C. Knowles, I. Rehman, I. Parkin, J.R.G. Evans, J.A. Darr, J. Comb. Chem. 11 (2009) 829-834.

[22] X. Du, D. Zhang, L. Shi, R. Gao, J. Zhang, J. Phys. Chem. C 116 (2012) 10009-10016. [23] N. Yi, R. Si, H. Saltsburg, M. Flytzani-Stephanopoulos, Appl. Catal. B: Environ. 95 (2010) 87-92.

[24] W-I. Hsiao, Y-S. Lin, Y-C. Chen, C-S. Lee, Chem. Phys. Lett. 441 (2007) 294-299.

[25] I. Ilgaz, B. Bayram, H. Sohn, P. Gawade, J.T. Miller, U.S. Ozkan, Appl. Catal. A: Gen. 449 (2012) 47-58.

[26] W. Hong, Z. Lijuan, L. Miao, L. Yuan, B. Xue, J. Rare Earths 31 (2013) 565-571.

[27]X. Liu, K. Zhou, L. Wang, B. Wang and Y. Li, J. Am. Chem. Soc. 131 (2009) 3140-3141.

[28] D. Zhang, X. Du, L. Shi, R. Gao, Dalton Trans. 41 (2012) 14455-14475.

[29] Q. Wu, F. Zhang, P. Xiao, H.S. Tao, X.Z. Wang, Z. Hu, Y.N. Lu, J. Phys. Chem. C 112 (2008) 17076-17080.

[30] T. Désaunay, G. Bonura, V. Chiodo, S. Freni, J.P. Couzinié, J. Bourgon, A. Ringuedé, F. Labat, C. Adamo, M. Cassir, J. Catal. 297 (2013) 193-201.

[31] Z.L. Wu, M.J. Li, J. Howe, H.M. Meyer, S.H. Overbury, Langmuir 26 (2010) 1659516606. 
[32] X.Q. Wang, J.C. Hanson, A.I. Frenkel, J.Y. Kim, J.A. Rodriguez, J. Phys. Chem. B 108 (2004) 13667-13673.

[33] W. Xu, R. Si, S.D. Senanayake, J. Llorca, H. Idriss, D. Stacchiola, J.C. Hanson, J.A. Rodriguez, J. Catal. 291 (2012), 117-126.

[34] A. Karpenko, R. Leppelt, V. Plzak, R.J. Behm, J. Catal. 252 (2007) 231-242.

[35] Y. Chen, H. Wang, R. Burch, C. Hardacre, P. Hu, Faraday Discuss., 152 (2011) 121133.

[36] N.J. Divins, I. Angurell, C. Escudero, V. Pérez-Dieste, J. Llorca, Science 346 (2014) $620-623$.

[37] Y. Qi, J. Wu, H. Zhang, Y. Jiang, C. Jin, M. Fu, H. Yang, D. Yang, Nanoscale 6 (2014) 7012-7018.

[38] C. Cienfuegos, E.P. Isoardi, G.D. Barrera, Phys. Rev. B 71 (2005) 144202-144208. 


\section{Figure legends}

Figure 1. Hydrogen yield $\left(\mathrm{Y}_{\mathrm{H} 2}\right)$ obtained at different temperatures over the $\mathrm{CeO}_{2}$ supports and over the respective $\mathrm{RhPd} / \mathrm{CeO}_{2}$ catalysts. $\mathrm{S} / \mathrm{C}=3, \mathrm{WHSV}=9 \cdot 10^{-3} \mathrm{NL}_{\text {gas }} \cdot g_{\text {catalyst }}{ }^{-1} \cdot \mathrm{s}^{-1}$, $\mathrm{GHSV}=10^{4} h^{-1} . \mathrm{Y}_{\mathrm{H} 2}=\mathrm{n}_{\mathrm{H} 2} / 6 \mathrm{n}_{\mathrm{EHOH}, \mathrm{in}}$.

Figure 2. Product selectivity on a dry basis obtained over the $\mathrm{RhPd} / \mathrm{CeO}_{2}$ catalysts, $\mathrm{S} / \mathrm{C}=3$, WHSV $=9 \cdot 10^{-3} \mathrm{NL}_{\text {gas }} \cdot g_{\text {catalyst }}{ }^{-1} \cdot \mathrm{s}^{-1}$, and GHSV $=10^{4} \mathrm{~h}^{-1}$.

Figure 3. STEM images of the $\mathrm{RhPd} / \mathrm{CeO}_{2}-\mathrm{P}$ catalyst.

Figure 4. STEM images of the $\mathrm{RhPd} / \mathrm{CeO}_{2}-\mathrm{C}$ catalyst.

Figure 5. STEM images of the $\mathrm{RhPd} / \mathrm{CeO}_{2}-\mathrm{R}$ catalyst. The EEL spectra correspond to the $\mathrm{CeO}_{2}$ support and the $\mathrm{RhPd}$ nanoparticles supported on $\mathrm{CeO}_{2}$.

Figure 6. XRD profiles recorded under operando conditions over catalysts $\mathrm{RhPd} / \mathrm{CeO}_{2}-\mathrm{P}(\mathrm{a})$, $\mathrm{RhPd} / \mathrm{CeO}_{2}-\mathrm{C}(\mathrm{b})$ and $\mathrm{RhPd} / \mathrm{CeO}_{2}-\mathrm{R}(\mathrm{c})$ under $\mathrm{O}_{2}$ at $573 \mathrm{~K}(\square), \mathrm{H}_{2}$ at $573 \mathrm{~K}(\mathrm{\circ})$ and ESR at $873 \mathrm{~K}(\Delta)$. 


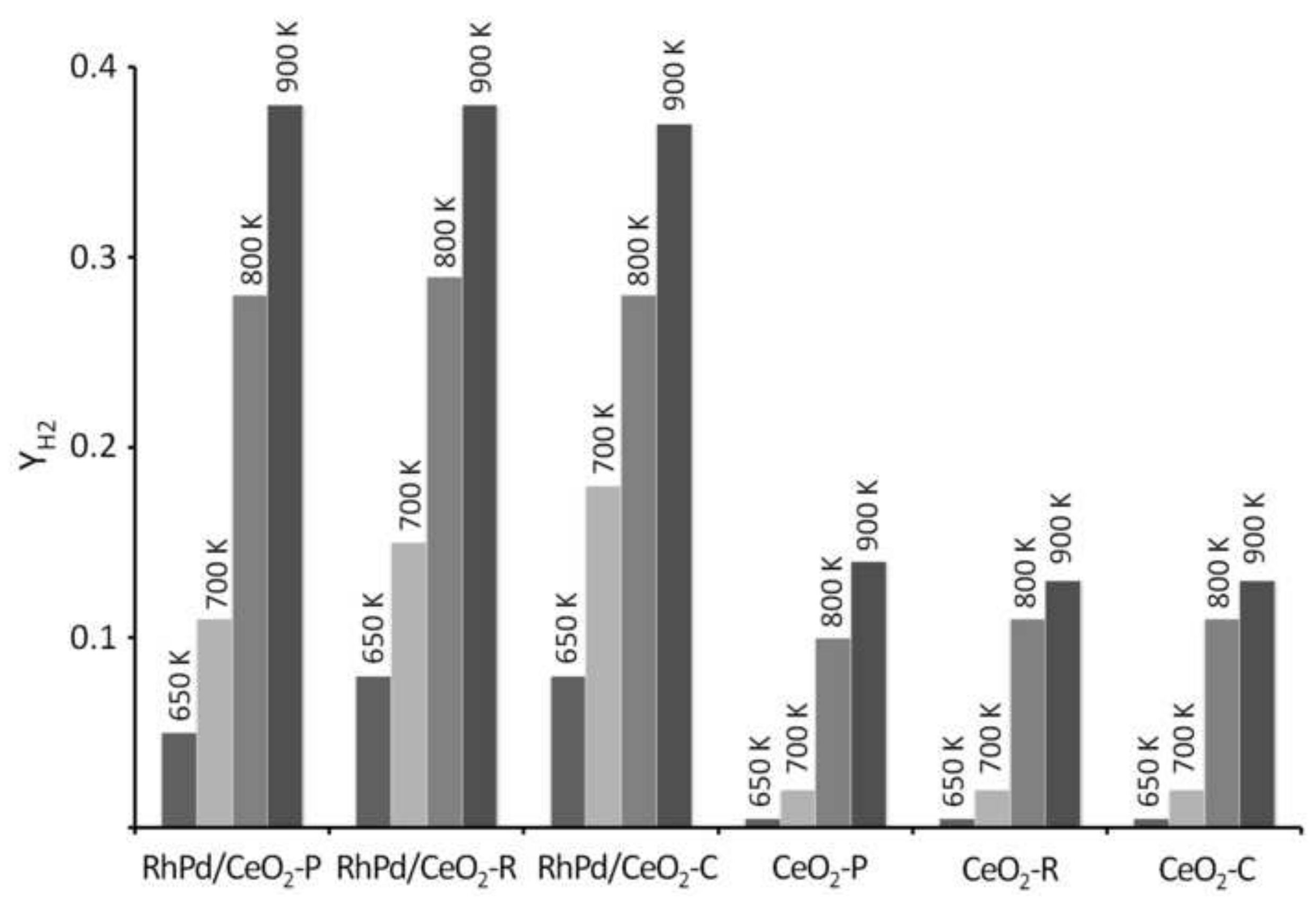




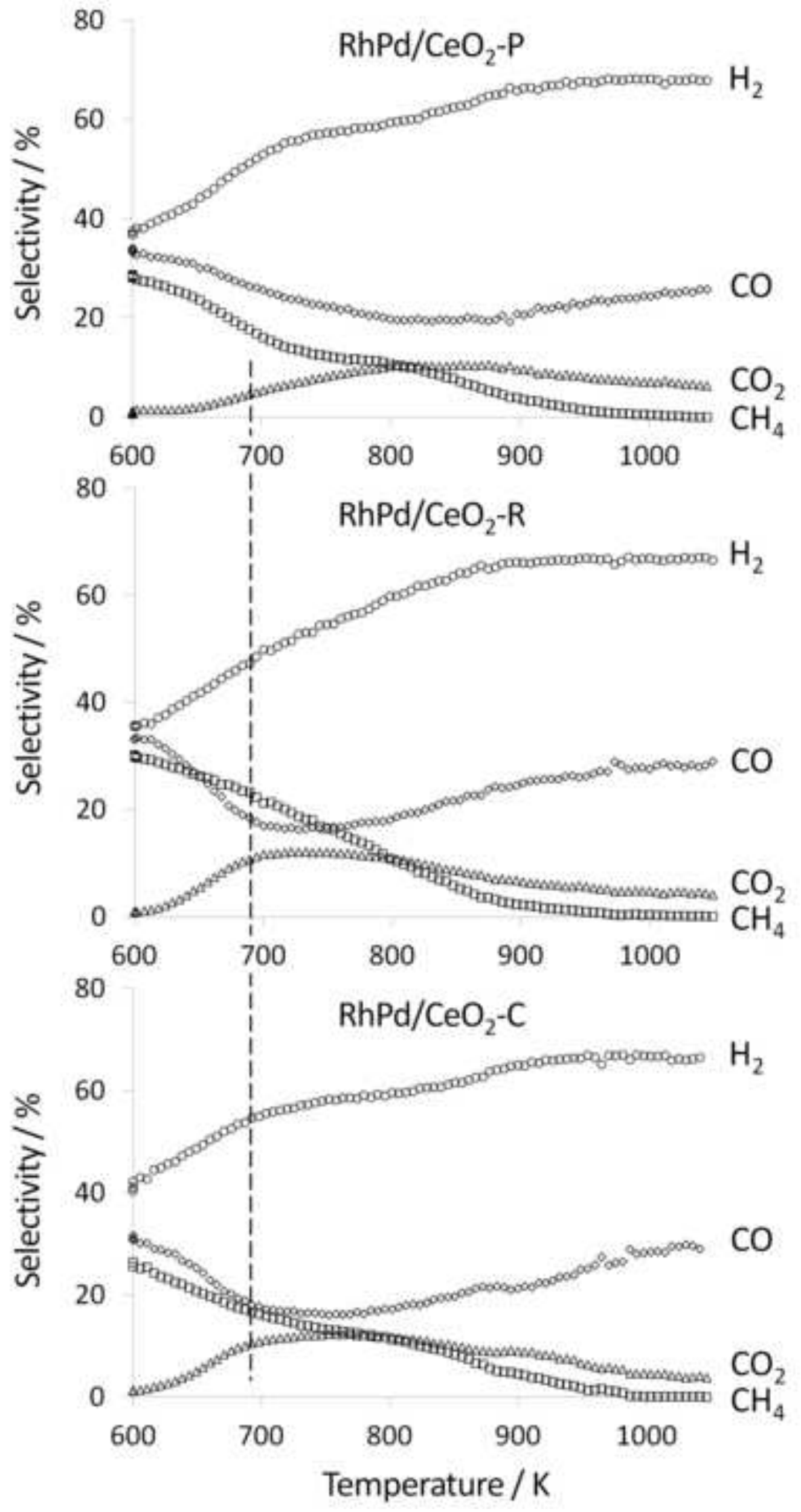



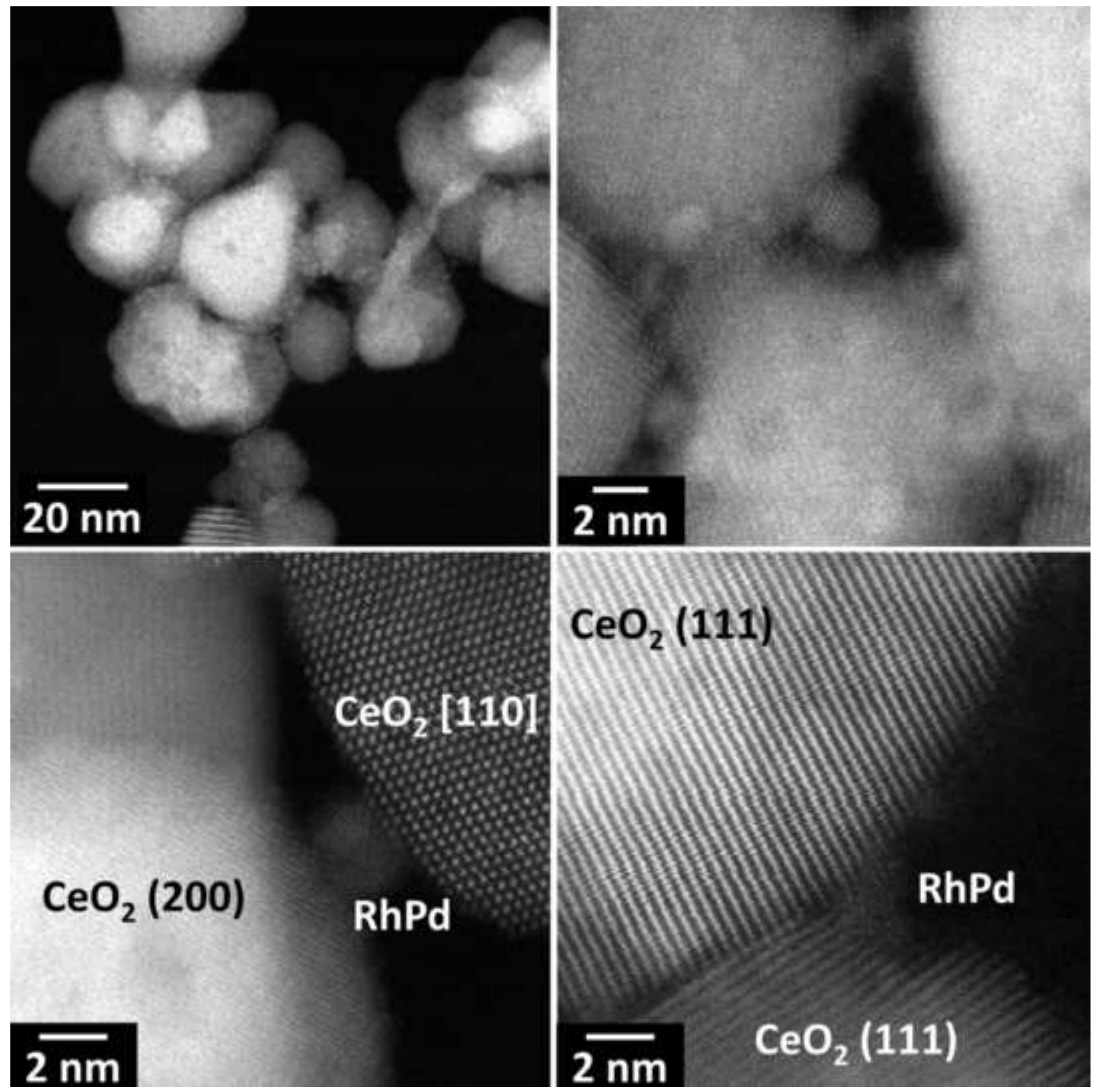

$\mathrm{CeO}_{2}(111)$
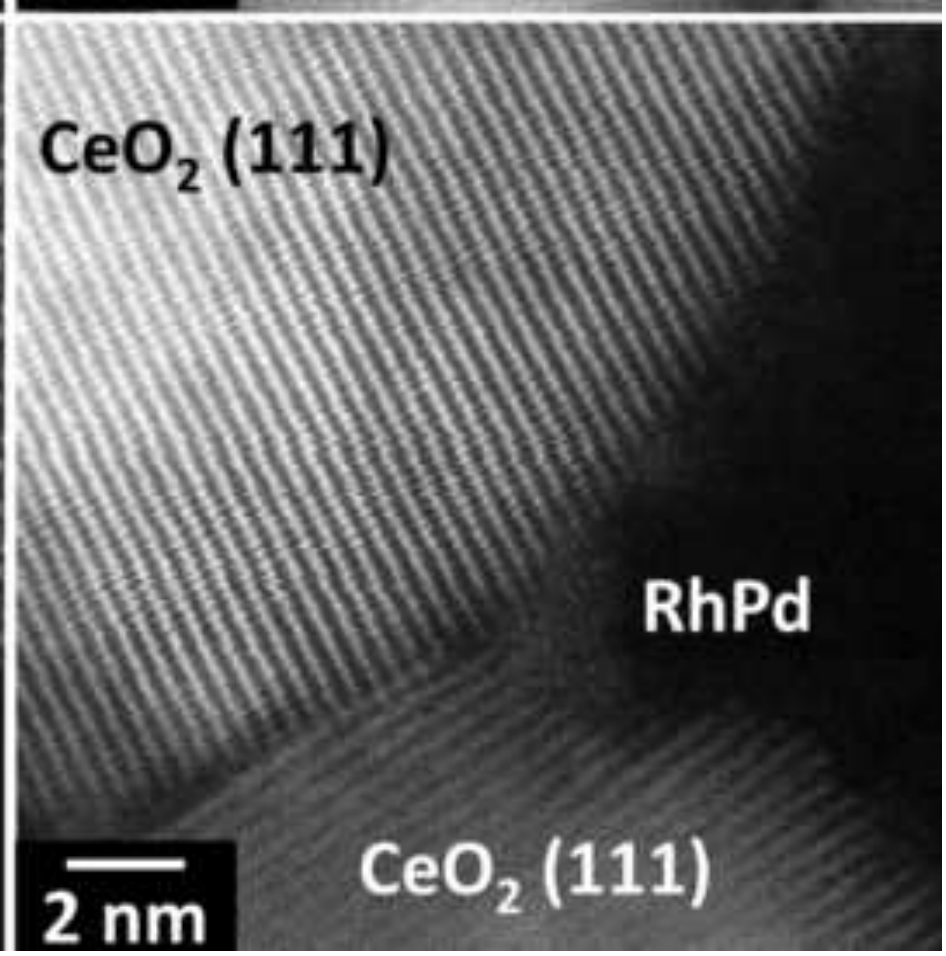

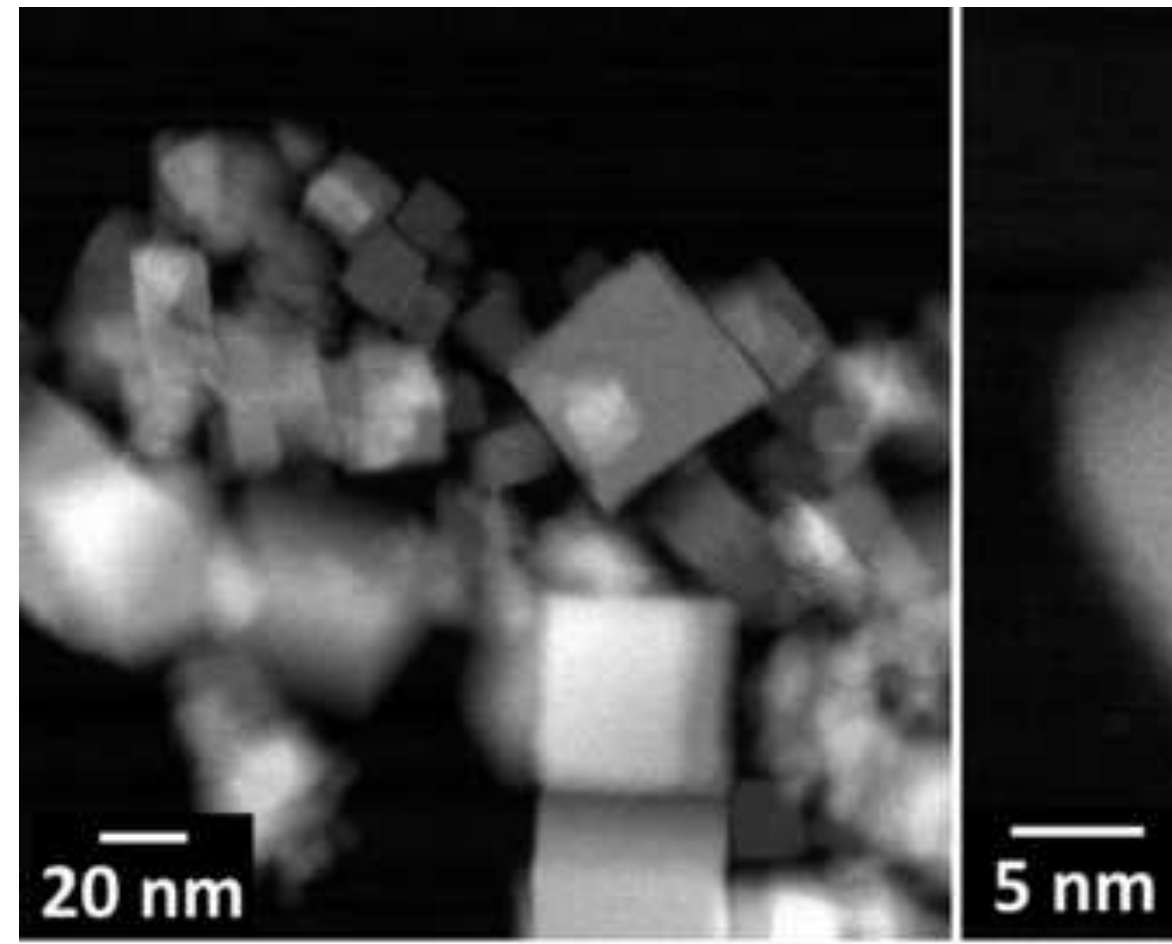

RhPd

RhPd

$\mathrm{CeO}_{2}[100]$

\section{$\mathrm{CeO}_{2}[100]$}
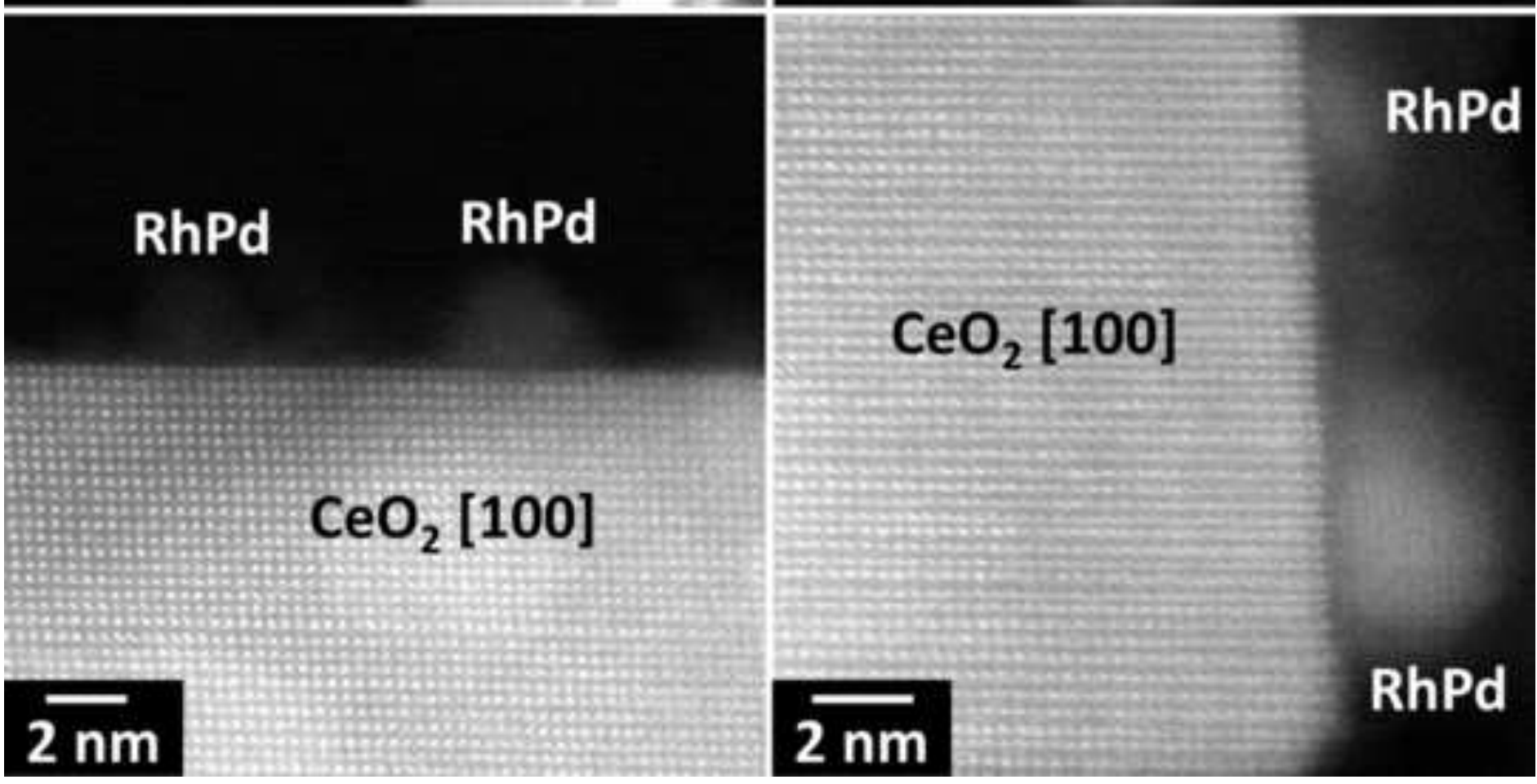
Figure 5
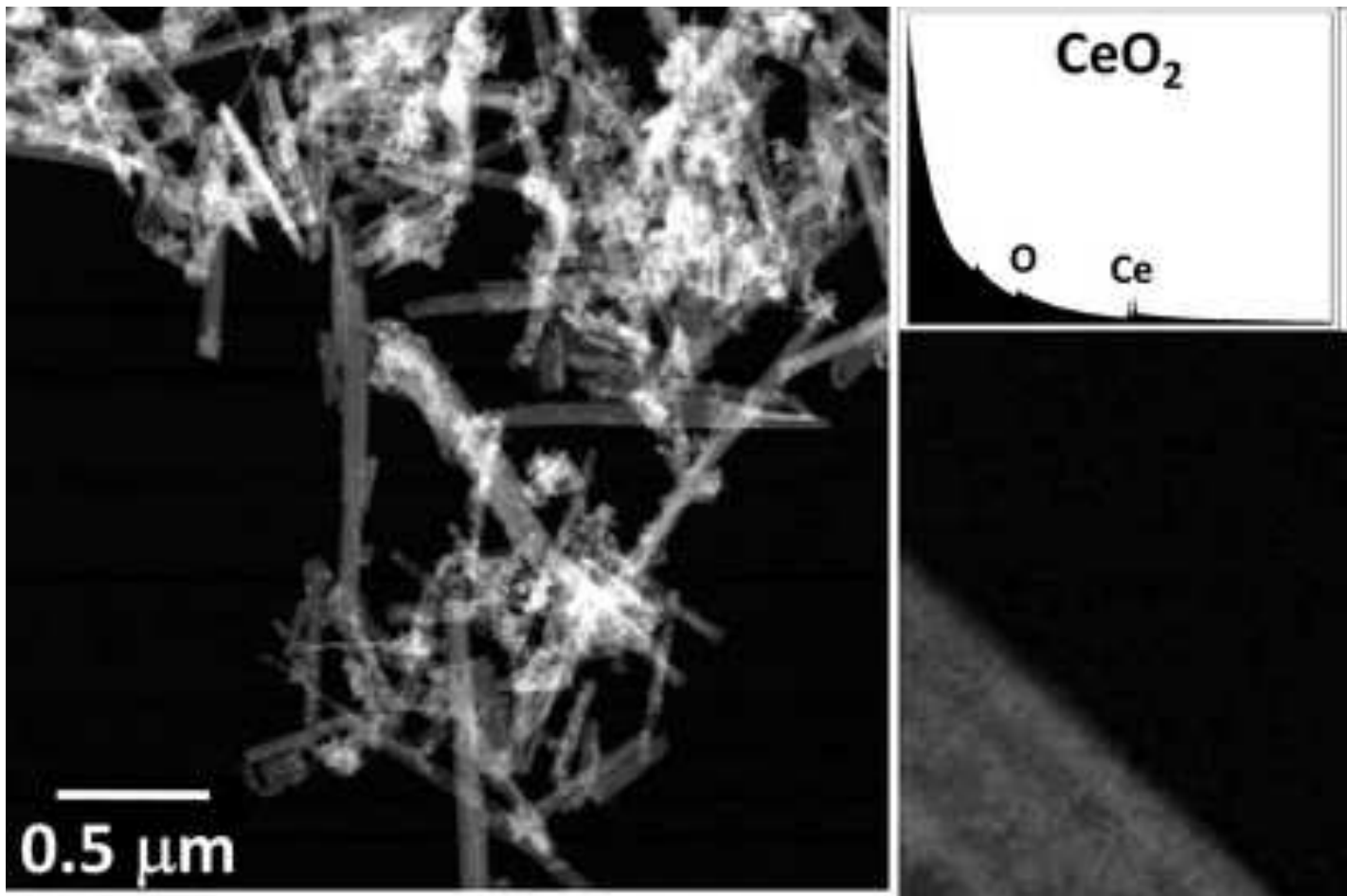

$\mathrm{RhPd} / \mathrm{CeO}_{2}$

Rh

Pd

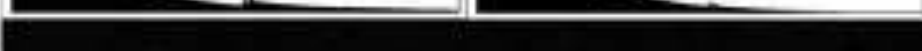

RhPd

RhPd

$\mathrm{CeO}_{2}(220)$

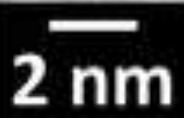

$20 \mathrm{~nm}$ 


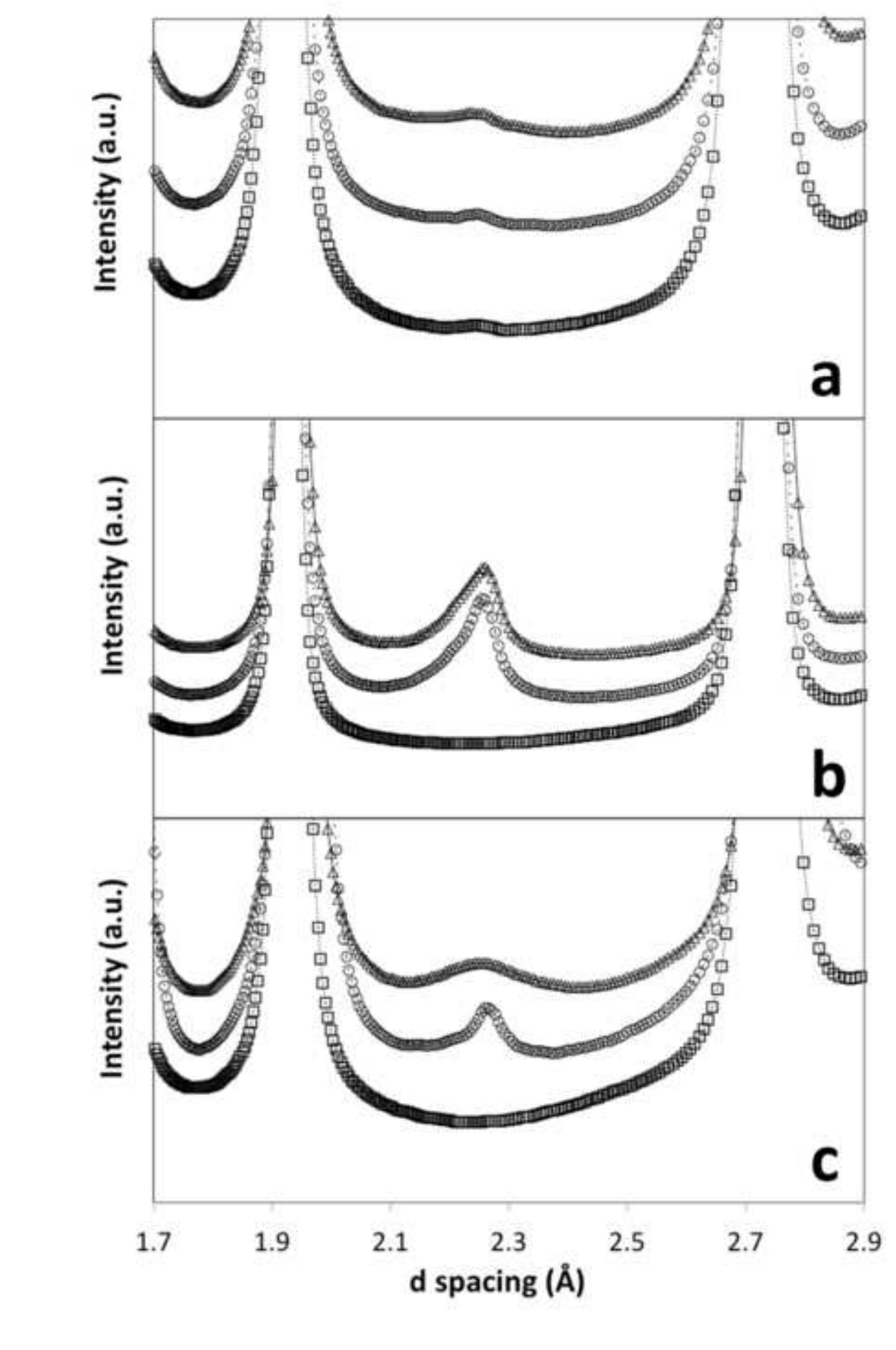

Figure 6

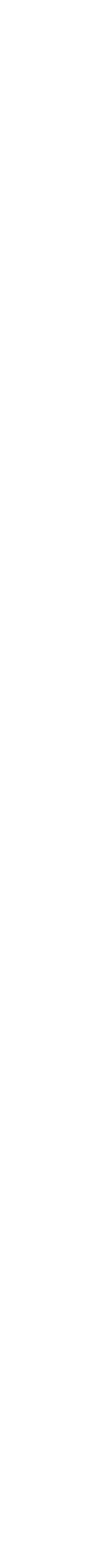

\section{Figure}

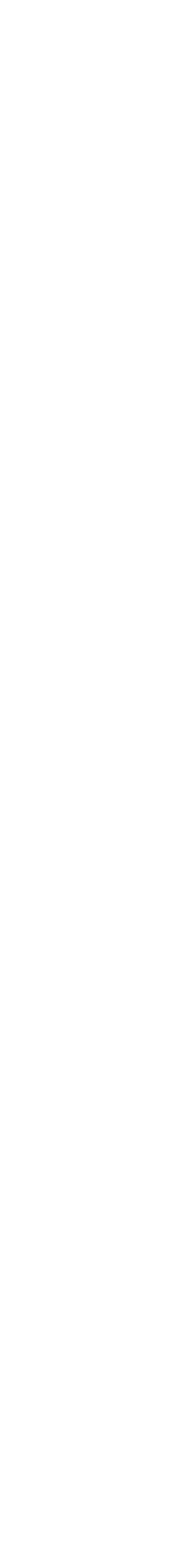

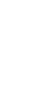

